\title{
Dialogia
}

e-ISSN: 1983-9294

\section{Violências entre pares no contexto escolar: razões e enfrentamentos ${ }^{1}$}

\author{
Peer violence in school context: reasons and confrontations
}

Éder Soares Sá Britto

Mestre em Educação pela Universidade Nove de Julho. Professor de Filosofia na Rede Oficial de Ensino do Estado de São Paulo. São Paulo - SP - Brasil dom.eder@hotmail.com

Jason Ferreira Mafra

Doutor em Educação pela Universidade de São Paulo. Diretor do Programa de Pós-Graduação Profissional (PROGEPE) em Educação da Universidade Nove de Julho. São Paulo - SP - Brasil

jasonmafra@gmail.com

Resumo: Este artigo tem por objeto de estudo as violências na escola ocorridas entre estudantes no contexto escolar. Partiu-se do princípio sociológico de que as ações de violência entre pares são resultado de conflitos existentes na escola que, em certa medida, reproduz, nesse microssistema, conflitos mais gerais da sociedade. Para aprofundar essa discussão, buscou-se responder às seguintes perguntas: Como as violências se apresentam na escola? Com vistas à superação dos conflitos que geram as violências entre pares, haveria na escola espaços para o diálogo rumo à cultura da paz? Para tanto, buscou-se caracterizar a escola e os protagonistas desse contexto pesquisado, identificar e analisar os fatores causais de violências na escola e suas consequências; analisar as manifestações de conflitos geradores de violências e encontrar na escola possibilidades para o diálogo. O universo empírico da pesquisa delimitou-se a uma escola pública estadual situada em uma região de segregação socioespacial do município de São Paulo. Os sujeitos da pesquisa foram estudantes do ensino médio regular que vivenciaram conflitos e atos de violência no ambiente escolar. Tomando como fundamento teórico a teoria paulo-freiriana, a metodologia utilizada foi de cunho qualitativo, cujos instrumentos de coletas de dados foram: questionário aplicado para 100 estudantes de ensino médio; análise do livro de ocorrências escolar; diálogos sobre o tema em formato de círculos epistemológicos; observação de campo. O processo de investigação, ocorrido no período de 2017 e 2018, resultou, também, em momentos de pesquisa-ação com vistas a estimular a consciência crítica dos estudantes sobre as práticas de violências e promover o diálogo como instrumento de enfrentamentos de conflitos e violências. Tendo em vista as exigências de uma pesquisa realizada em um programa de pós-graduação profissional, a partir dos resultados da pesquisa, foi sistematizado junto aos estudantes um conjunto de códigos de relações escolares pautados no diálogo e na conscientização dos escolares com foco no enfrentamento das violências no contexto escolar. Essa proposta de intervenção foi entregue à escola a fim de auxiliá-la em suas ações de superação das violências.

Palavras-chave: Violências na escola. Violências entre pares. Estudantes de ensino médio. Diálogo. Círculo epistemológico.

Abstract: This article has as object of study the violence at school that occurred among students in the school
context. It was based on the sociological principle that actions of peer violence are the result of conflicts
existing in the school that, to a certain extent, reproduces, in this microsystem, the more general conflicts of
society. To deepen this discussion, we sought to answer the following questions: How do violence present itself
in school? With a view to overcoming the conflicts that generate violence between couples, would there be
room in schools for dialogue towards the culture of peace? To this end, it was sought to characterize the school
and the protagonists of this context researched, to identify and analyze the causal factors of violence in the
school and its consequences; to analyze the manifestations of conflicts generators of violence and find in
schools possibilities for dialogue. The empirical universe of the research was defined as a public state school
located in a region of socio-spatial segregation of the city of São Paulo. The research subjects were regular
high school students who experienced conflict and violence in the school environment. Taking as theoretical 
basis the Pauline theory, the methodology used was qualitative, whose instruments of data collection were: a questionnaire applied to 100 high school students; analysis of the textbook of school occurrences; dialogues on the subject in the form of epistemological circles; field observation. The investigation process, occurred in the period 2017 e 2018, it also resulted in moments of research and action aimed at stimulating students' critical awareness of violence practices and promoting dialogue as an instrument of conflict and violence. In view of the requirements of a research conducted in a professional postgraduate program, based on the results of the research, the students were systematized with a set of codes of school relations based on the dialogue and awareness of schoolchildren focusing on coping with violence in the school context. This intervention proposal was delivered to the school in order to assist it in its actions of overcoming violence.

Keywords: Violence in school. Peer violence. High school students. Dialogue. Epistemological circle.

\section{Introdução}

Este artigo trata das violências no meio escolar, precisamente aquelas desencadeadas entre pares. Para tanto, examinou-se suas manifestações a partir do contexto de estudantes do ensino médio, de uma escola púbica da cidade de São Paulo. A temática violência entre pares obteve destaque singular no presente trabalho por se constituir um dos fenômenos existentes, em graus distintos, em todo espaço escolar, mas que, por diferentes razões, não recebe a devida atenção das pessoas envolvidas no processo educacional. Revela-se, neste sentido, como sendo uma problemática institucional e social. Analisar a cultura institucional favorece, de certo modo, não só o entendimento da manifestação desse fenômeno, mas, ao mesmo tempo, permite-nos verificar a interferência da escola no comportamento dos estudantes. Em que medida a violência entre pares ocorre dentro da escola e em que medida o modo como a escola se apresenta colabora com o desenvolvimento de tal comportamento? Para compreensão do contexto mais amplo da violência entre estudantes, foi realizada uma abordagem histórica sobre o fenômeno da violência, compreendendo-o como um fenômeno cultural e sempre atual.

São muitas as tentativas de respostas diante dos mesmos e anômalos comportamentos de desumanização, decorrentes das injustiças incrustadas na sociedade brasileira e em suas instituições; tantas ao ponto de nos perdermos no tempo e já não mais sabermos dizer com exatidão sobre o início da relação entre educação e violência.

A violência surge como uma realidade de difícil compreensão, intrínseca à vida das pessoas. Autores de distintas correntes e campos de estudos já desenvolveram pesquisas que atestam a ideia de que a violência circunda as ações humanas em todas as épocas, tempos e lugares. Priotto (2011) alega que a violência se faz presente em qualquer cultura sob diferentes aspectos, características e significados, caminhando com o desenvolvimento da vida social e se deixando explicar a partir de dimensões culturais, históricas, políticas, sociais, econômicas e psicossociais sempre inerentes às sociedades humanas. Dahlberg e Krug (2006), no artigo intitulado Violência: um problema global de saúde pública, demonstram que as 
manifestações de violências na sociedade aumentam frequentemente, pois todos os anos são registrados em diversos países casos em que mais de um milhão de pessoas perdem suas vidas sendo vítimas de práticas violentas. Outro sem número de seres sofrem ações não fatais resultantes de agressões físicas ou violências coletivas.

A educação também faz parte desse cenário violento. Mas o que leva a escola se tornar um espaço produtor e reprodutor dessas formas de violência? Seria outra maneira de fazer educação, capaz de coibir violências em seu espaço? Quais práticas a escola, que deseja romper com o modelo tradicional, precisa adotar? Essas e outras questões que relacionam escola e violência já foram objetos de discussão e pesquisas. Para Paulo Freire (1967, p. 103), a escola precisa se ressignificar enquanto espaço educativo. Notadamente, a sala de aula, arena histórica da educação transmissora e bancária, precisa superar os seus vícios e tornar-se um lugar realmente educativo. De acordo com o educador brasileiro,

\begin{abstract}
Em lugar de escola, que nos parece um conceito, entre nós, demasiado carregado de passividade, em face de nossa própria formação (mesmo quando se lhe dá o atributo de ativa), contradizendo a dinâmica fase de transição, lançamos o Círculo de Cultura. Em lugar de professor, com tradições fortemente "doadoras", o Coordenador de Debates. Em lugar de aula discursiva, o diálogo. Em lugar de aluno, com tradições passivas, o participante de grupo. Em lugar dos "pontos" e de programas alienados, programação compacta, "reduzida" e "codificada" em unidades de aprendizado.
\end{abstract}

Freire (1987) observa, para além da escola, que os sujeitos oprimidos reagem buscando confrontar as intenções que articulam as ações opressoras. Esse confronto ocorre positivamente, quando se trata de um enfrentamento pedagogicamente consciente, ou negativamente, quando se trata de ampliar o processo de violência. Uma das ideias presentes em Pedagogia do Oprimido é a de que mulheres e homens oprimidos, quando assumem sua “vocação do ser mais" (FREIRE, 1987, p. 58), em um processo que se dá após a tomada de consciência do seu inacabamento, buscam maior humanização de si. Assim aquelas práticas individualistas, egoístas e mesquinhas são deixadas de lado e uma nova realidade humanizadora vai se constituindo, de forma mais fraterna e solidária, com menos opressão e menos injustiça. Mas esse processo é lento e difícil, especialmente em um ambiente social violento e excludente como no caso da escola pública brasileira.

\title{
1 Violências sociais e violência escolar
}

A violência, em suas multiplicidades de formas, não é um fenômeno isolado. Atinge toda a estrutura social, por isso alcança, é reproduzida e ganha legitimidade também na instituição escolar, ainda que a escola tenha suas próprias formas de violência, como 
demonstra Abramovay (2002), em diferentes estudos. Estudantes, de uma maneira ou de outra, estão envolvidos em tramas violentas no contexto escolar, ora como vítimas, ora como algozes, ora como espectadores. Se esse envolvimento por parte dos discentes é inevitável, já que a violência manifesta-se em todo o lugar, escutar o estudante é poder aproximar-se de suas experiências, é perceber o seu agir, suas possíveis posições, sendo vítima ou autor das violências, testemunha passiva ou cúmplice dos fatos. Estar junto ao estudante, dando-lhe o direito de expressar suas ideias, é observar e entender seus relatos numa perspectiva de melhor compreender a realidade que cerca tal fenômeno.

Como um microssistema social de uma sociedade violenta, a escola, em suas opções de agir diante de situações de conflito, torna-se corriqueiramente um espaço de violência e de indisciplina. Isso se dá num movimento ambíguo. De um lado, pelas ações que visam o cumprimento pleno das regras e das normas determinadas pela hierarquia profissional e sua autoridade; de outro, pela dinâmica dos seus grupos internos que estabelecem rupturas e permitem a troca de sentimentos conflitantes e interessados numa fusão impulsiva e provisória. Nesta lógica ambígua de relativa dependência e autonomia, pode-se entender que as escolas também produzem sua própria violência e sua própria indisciplina, não sendo apenas espaços que reproduzem, involuntariamente, formas de opressão, violências e conflitos do âmbito da sociedade em geral.

Constituída e agindo como toda e qualquer outra instituição social, a escola está delineada para que os sujeitos que dela fazem parte sejam todos "iguais". Todavia essa igualdade não se constitui como sinônimo de reconhecimento de justiça, mas de homogeneização, de forma a facilitar e a favorecer a direção, o controle e a dominação.

Para Durkheim (2015, p. 14), “[...] a educação consiste numa socialização metódica das novas gerações", de forma que executar processos por meio dos quais o estudante absorve regras é uma das funções da escola, passando a evidenciar a necessidade de uma disciplina escolar, de acordo com as condutas impostas para a convivência social. É a escola a serviço da sociedade, moldando com seus métodos as novas gerações que perpetuarão esse modelo de sociedade. Logo, nessa perspectiva, a despeito de seus propósitos declarados, a escola serve de espaço de manutenção e garantia de práticas abusivas e, portanto, opressoras, incrustadas nas relações sociais.

\section{Escola: produção e reprodução de violências}

As concepções que consideram urgente analisar os contextos em que se manifestam tanto as violências na escola (ocorrências dentro do espaço físico) quanto às violências 
escolares (produzidas ou reproduzidas pela instituição), com vistas a lhe atribuir sentidos e encontrar suas razões, não são inquietações novas. Pelo contrário, já em 1970, Pierre Bourdieu e Jean Claude Passeron, na clássica obra A reprodução: elementos para uma teoria geral do sistema de ensino, trazem, a partir do estudo da realidade francesa essa discussão. Dentre outros propósitos da obra, os autores descrevem o contexto em que se desenvolve a dinâmica escolar como centro das tensões relativas à produção e manutenção das desigualdades e da relação desta com a desigualdade social.

Na compreensão do sociólogo Pierre Bourdieu (1989), o episódio repetidamente praticado pela escola para punir as transgressões de condutas morais em seu espaço, uma espécie de contra-violência escolar, é classificado como violência simbólica. O autor se debruça sobre a complexidade da violência simbólica enquanto processo de reprodução das desigualdades sociais e considera que a instituição escolar tem o papel social de reproduzir e legitimar as desigualdades, perpetuando-as. Demonstra Bourdieu (1989, p. 99) que:

\footnotetext{
Os produtos dominados de uma ordem dominada por forças enfeitadas de razão (como as que agem através dos vereditos da instituição escolar ou através dos ditames dos especialistas econômicos) não podem senão atribuir seu assentimento ao arbitrário da força racionalizada.
}

O autor compreende que as desigualdades existentes na sociedade são projetadas e confirmadas no espaço escolar, que age com argumento de autoridade. Assim, deixa de colaborar com a promoção humana, desvaloriza ou desconsidera as diferentes culturas, histórias e experiências de seus estudantes, não favorecendo as devidas condições para a igualdade e omitindo-se em romper com estruturas culturais e sociais dominantes.

O trabalho de Bourdieu, ao demonstrar o alcance reprodutivo das múltiplas formas de violência na escola é notável, mas não dá conta de toda a realidade. Se, de um lado, a escola é um micromundo de reprodução social; de outro, ela comporta, por sua natureza dialética, os lugares de criação e enfrentamento da realidade opressora. É o caráter contraditório de sua realidade que a torna um lócus, apesar de tudo, possível de mudança.

Freire (1979) observa que, em dado momento da construção da consciência, especialmente ao superar a consciência ingênua, muitos sujeitos se rebelam e não aceitam tacitamente atitudes opressoras. Ações opressoras provocam nos oprimidos o desejo de mudanças e a superação das contradições em que se acham. No momento, então, de ação movida pela conscientização, oprimidas e oprimidos lutam por transformações da realidade a que estão subordinados e, libertando-se das amarras dessa opressão, podem libertar aqueles que os oprimem. Eis aí, a possibilidade do surgimento dos novos seres, da nova sociedade, 
da nova educação.

\section{Práxis freiriana como processo de transformação}

A única maneira que alguém tem de aplicar, no seu contexto, alguma das proposições que fiz é exatamente refazer-me, quer dizer, não seguir-me. Para seguir-me, o fundamental é não me seguir. (FREIRE; FAUNDEZ, 1985, p. 41).

Freire nunca escreveu um livro especificamente sobre violência escolar. Em alguns momentos, particularmente em seminários e conferências, tratou perifericamente desse tema. Por outro lado, ao observarmos o conjunto de sua obra, percebemos essa preocupação, já que toda a sua proposta debruça-se, em primeiro lugar, para a compreensão (denúncia) das múltiplas formas de violência, a partir da leitura crítica do mundo, e, posteriormente, para a proposição (anúncios) de ações culturais para enfrentamento e superação das estruturas opressoras.

Com suas inquietações e proposições, Freire motivou a esperança e a confiança na cultura, apresentando a educação como uma forma central e, portanto, necessária para levar o sujeito marginalizado da sociedade, sobretudo, pelo seu analfabetismo, a fazer-se no mundo. Considerando sua proposta de reinvenção da práxis, praticar os ensinamentos de Freire não é fazer exatamente como ele fez, mas sim fazer o que ele faria nesta época se nela estivesse. Portanto, agir como Paulo Freire não é precisamente imitá-lo. A educadora e o educador que assim o fizessem, pela própria dialética da proposta freiriana, estariam negando essa teoria que sempre se preocupou em responder questões atuais do mundo em que se vive. Em Freire, as ações de reinvenção da práxis devem estar ligadas às realidades sociais vigentes. Dessa maneira, no contexto aqui abordado, fazer como propõe o educador significa trazer para a escola um olhar crítico e nela atuar com esperança, liberdade e consciência.

No livro Cartas a Cristina (FREIRE, 1994), pode-se compreender a dialética entre o ser humano e o mundo apresentada por ele. Ambos, pessoa e mundo, são inacabados, por isso estão fazendo-se, e é na constante busca de querer "ser mais" que o ser humano entra no processo de ação-reflexão-ação, condição para a transformação da realidade objetiva. Segundo Freire, esses efeitos da práxis se refletem na transformação do próprio sujeito que reflete e age. A implicação da conscientização é o compromisso dos seres humanos com o mundo. Segundo Freire (1979), uma vez criticamente conscientes de sua realidade de opressão, aqueles que são forçados a viver à margem da sociedade preparam-se para realizar ações que visem à superação de sua condição de oprimidos.

O autor mostra que a educação crítica e engajada precisa assumir o caráter libertador, 
conscientizador, com esperança e em direção a uma cultura pacificadora. A cultura pacificadora não se confunde com uma cultura passiva, imobilizadora. Ao contrário, em Freire, a luta por justiça social é o único caminho para se enfrentar a violência em seu sentido mais amplo (econômica, social, cultura, simbólica). Em certa ocasião, recordou que, ao promover a superação das realidades sociais perversas, a educação constrói um caminho para a justiça social, ou seja, para a paz. Assim afirmou em seu breve discurso, ao ser contemplado com o "Prêmio UNESCO da Educação para a Paz", em Paris:

De anônimas gentes, sofridas gentes, exploradas gentes, aprendi, sobretudo, que a paz é fundamental, indispensável, mas que a paz implica lutar por ela. A paz se cria, se constrói na e pela superação de realidades sociais perversas. A paz se cria, se constrói na construção incessante da justiça social. Por isso, não creio em nenhum esforço chamado de educação para a paz que, em lugar de desvelar o mundo das injustiças o torna opaco e tenta miopizar as suas vítimas. (GADOTTI, 1996, p. 52).

No livro Conscientização: teoria e prática da libertação, Paulo Freire (1979) expõe sua opção pedagógica, fundamentada na ideia de transformação da realidade e superação das injustiças sociais através de uma educação voltada à conscientização. Uma vez que a compreensão do mundo passa pela consciência, os atores sociais precisam da conscientização para que sua relação com o mundo não seja uma relação de submissão, mas sim relação de ação. $O$ processo de conscientização não se confunde com a tomada de consciência. A passagem da consciência inicial ou ingênua para uma consciência mais elaborada e crítica é um processo que ocorre lentamente. A conscientização estrutura-se a partir da reflexão crítica sobre a prática. Esse "pensar sobre", "ad-mirando" a realidade, embora não suficiente, é condição para a superação da consciência ingênua. Freire (1979), ao pontuar que a tomada de consciência ainda não é conscientização em si, afirma que ela ocorre somente no ato da açãoreflexão-ação dos atores sociais sobre o mundo.

Dessa forma, cada estudante a partir de sua realidade vivida, ou seja, da sua dimensão "sócio-histórica-cultural", pode, pelo exercício da reflexão crítica, estruturar uma consciência do lugar que ocupa na sociedade, conscientizando-se também daquilo que o oprime, condição para o trabalho de libertação. As proposições de Freire sobre uma educação fundada no diálogo, como exercício de leitura crítica do mundo e de intervenção na realidade, serviram de base para conhecermos e entendermos a escola pesquisada, seu contexto e modo de ser.

\section{Escola, que lugar é esse?}


A escola, objeto desta pesquisa, lida com as mais variadas questões de indisciplina de maneira tradicional, quase sempre sem a prática do diálogo para promover discussão e reflexão sobre as ocorrências.

Situada no extremo leste da cidade de São Paulo, em São Miguel Paulista, região periférica da Capital, essa unidade escolar é marcada por inúmeros problemas de segurança pública, decorrente, dentre outros aspectos, do alto consumo e tráfico de drogas estabelecido na região, situação que faz desse espaço um lugar de constantes ocorrências de roubos e furtos. As famílias que constituem a comunidade escolar são muito pobres, em geral, sem a estrutura básica para viver de forma minimamente digna. A baixa escolaridade dos responsáveis ou familiares das crianças e jovens estudantes também é um fator comum entre as famílias. Suas residências são casas modestas e sem o mínimo de conforto, quase sempre inacabadas, de alvenaria simples. As piores são moradias improvisadas, casebres feitos em madeira e restos de materiais de construção encontrados pelas ruas do bairro.

A estrutura urbana oferecida pelos órgãos públicos para essas famílias limita-se ao fornecimento de água tratada e encanada, eletricidade, iluminação pública muito precária e pavimentação em péssimas condições. Vale destacar que, mais de uma década após ser sancionada a Lei Federal n 11.445/2007, que obriga a universalização do saneamento básico mínimo, ainda existem naquela região muitas casas sem acesso à rede pública de esgoto.

A escola estadual de educação básica ali criada, como tantas no Estado de São Paulo, desenvolve suas atividades com parcos recursos, oferecendo três segmentos de ensino para seu público local (fundamental I; fundamental II; ensino médio). Há ainda na região um posto policial com baixo efetivo militar, na avaliação de muitos moradores da região.

Importa-se recordar que essas condições de precariedade material, comum às escolas estaduais das periferias de São Paulo, geram um problema ainda maior para a realidade escolar. Em geral, são lugares marcados por uma grande instabilidade pedagógica e de gestão, dentre outros aspectos, pelo fato de que muitos profissionais que ali chegam tão logo se organizam para conseguir transferências às unidades escolares fora da extrema periferia, buscando, portanto, estabelecerem-se em escolas de regiões menos carentes e vulneráveis.

\section{Percurso investigativo}

Fundamentado na perspectiva epistemológica freiriana, conforme já descrito, o estudo, além dos aportes bibliográficos, resulta de levantamentos de natureza empírica. Para tanto, no contexto da mencionada escola, foram realizados coleta de dados e informações a partir de registros etnográficos, apontamento de conversas, aplicação de questionário e 
discussões em formato de círculos epistemológicos. Como sistemática para levantamento de informações em profundidade, utilizou-se, aqui, também, a observação participante, enquanto metodologia investigativa, não apenas para construir credibilidade junto aos estudantes, mas, também para fazê-los passar de meros informantes a colaboradores da pesquisa. No levantamento de dados, em profundidade, organizado em forma de círculos epistemológicos, aos alunos e alunas, foram apresentadas as ideias e os propósitos da pesquisa, de forma a construir uma maior interação com os sujeitos, descobrindo-se os momentos de quando intervir ou quando aguardar a intervenção, assim como sobre quais perguntas fazer em cada momento.

Cada etapa metodológica significou um avanço nas dinâmicas dos círculos epistemológicos. É importante destacar que os círculos epistemológicos foram sistematizados a partir dos princípios dos círculos de cultura bastante utilizados e difundidos por Freire. Esse procedimento acabou por oferecer melhores ferramentas para refletir e discutir de forma mais contextualizada o tema das violências entre estudantes na escola. De acordo com Romão et al. (2006, p. 10):

O Círculo Epistemológico apresenta-se, portanto, como um método crítico e, ao mesmo tempo, sensível, pois se realiza sob um conjunto de condições que, já à primeira vista, oferece uma série de vantagens sobre outros métodos de pesquisa: conjuga técnicas consolidadas de coleta de dados (entrevista coletiva semiestruturada, discussão de grupo e observação participante), para produzir dados no espaço grupal, de forma dinâmica, dialógica e interacional.

Os dois círculos epistemológicos foram realizados por meio de cada etapa da metodologia desenvolvida, da observação atenta do espaço e conversas informais com os estudantes, aplicação de questionário, análise dos resultados e do livro de ocorrências, discussões em grupos até a conclusão com a elaboração da proposta de intervenção pedagógica.

Do levantamento quantitativo, participaram 100 alunos, convidados pelo pesquisador que também é professor das turmas de ensino médio da referida escola. Desse conjunto, 46 estudantes cursavam os primeiros anos do ensino médio, sendo 25 meninas e 21 meninos; 35 estudantes dos segundos anos do ensino médio, sendo 19 meninas e 16 meninos; 19 estudantes dos terceiros anos do ensino médio, sendo 11 meninos e 8 meninas. Esses participantes responderam a um questionário com perguntas em torno das ocorrências mais comuns e frequentes em uma escola por meio da ferramenta digital disponibilizada pelo serviço virtual Google Doc's. Os 100 sujeitos da pesquisa foram estimulados a responder o questionário subdividido em quatro blocos de perguntas sobre violências no cotidiano escolar. As referidas questões foram organizadas em situações em que os sujeitos pudessem se reconhecer entre os causadores, as vítimas ou apenas testemunhas de ocorrências entre 
estudantes. O comprometimento dos implicados na pesquisa em responder às questões correspondeu a $80 \%$ dos convidados.

Estipulou-se um período de uma semana para que os estudantes convidados respondessem às questões. Os estudantes receberam um link para acessar o questionário. As participações se deram por meio de correio eletrônico pessoal. Cada estudante respondeu

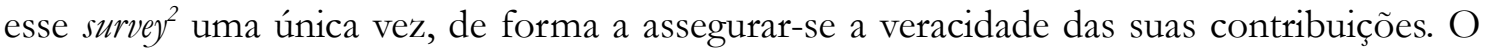
preenchimento do questionário não foi nominal. O propósito foi garantir maior liberdade de expressão aos participantes, evitando-se eliminar constrangimentos, de forma a extrair respostas fiéis à realidade.

Os acessos e as participações aconteceram em suas casas. Essa etapa se deu no primeiro semestre do ano letivo de 2018. Após os resultados obtidos, procedeu-se a sistematização de dados e informações e, em seguida, as análises de tais apontamentos.

Após aplicação desse levantamento, os participantes foram chamados a comparecer à escola num sábado predeterminado para apresentação dos resultados e análises das ocorrências. Em seguida, os estudantes foram convidados a iniciar a fase de elaboração de uma proposta de intervenção pedagógica inédita e viável capaz de ressignificar a existência dos sujeitos no espaço escolar, dar novo sentido à escola em suas vidas e melhorar convivências.

\section{Olhares e vozes estudantis sobre a violência: estabelecendo códigos de relações}

O diálogo, a reflexão e as discussões fizeram com que cada estudante participante dos círculos se aproximasse de uma consciência da realidade que o envolve e que também é construída por suas ações. Os círculos epistemológicos se transformaram em espaços de sistematização de códigos de convivência com o foco na superação dos conflitos, antes que esses venham a se transformar em novas violências.

Assim como ocorreu no encontro após coletas e análises das respostas ao questionário, houve, nos dois círculos epistemológicos, a exibição dessas respostas em gráficos de pizza e apresentação das transcrições das primeiras considerações que realizaram no encontro promovido depois que preencheram o questionário. Diante dos dados expostos, os participantes foram estimulados a repensar as práticas promotoras de violências destacadas pelo grupo. Objetivamos propiciar um ambiente favorável para a exposição das opiniões, dos sentimentos e de relatos no transcorrer dos círculos. Nos dois encontros, o pesquisador iniciou uma dinâmica envolvendo os presentes em um clima de descontração e relaxamento. 
Começar os círculos epistemológicos com aplicações de dinâmicas de grupo após a recepção favoreceu desinibição e descontração dos participantes e do pesquisador. A prática da atividade lúdica escolhida foi capaz de proporcionar maior concentração e envolvimento no debate que estava por vir. Os participantes foram convidados a formar um grande círculo e escreveram sobre alguns dos momentos vividos na escola que lhes trouxeram alegria e prazer em estar com os colegas. Momentos como festas, gincanas e campeonatos foram trazidos para o centro da dinâmica. Foi, então, perguntado aos participantes se naquelas ocasiões atitudes como preconceitos, ofensas e agressões apareceram nas relações de amizade; mas como que em uma só voz todos responderam: "Não".

Naquele momento, os participantes já estavam bem envolvidos e interessados no encontro. Logo após a resposta coletiva os presentes foram convidados a sentar em círculo para a etapa seguinte do encontro. Observava-se um ambiente de descontração e interação entre os presentes, o que permitiu dar início à explanação dos objetivos do círculo. Os grupos se constituíram conforme a disponibilidade dos sujeitos participantes. O grupo que se reuniu em um primeiro sábado constituiu-se com dezesseis estudantes (oito meninas e oito meninos, entre os três anos do Ensino Médio). O segundo encontro aconteceu no sábado seguinte, com um grupo formado por dezessete participantes e com maior participação feminina (doze meninas e cinco meninos, entre os três anos do Ensino Médio).

Para os estudantes de ambos os grupos, os círculos foram a oportunidade que tiveram de pensar, repensar e criticar livremente o universo escolar forjado por diferentes contribuições e intenções, fossem elas advindas de gestores de dentro e fora da escola, fossem elas articuladas pelos próprios estudantes. Segundo os participantes, aquela etapa da pesquisa foi a parte em que mais ficaram à vontade para falar, responder, questionar, contribuir. Nos dois grupos, concepções distintas sobre violência surgiram, porém todas e todos percebiam que tudo o que foi apresentado no questionário e nas falas precisava ser superado.

As falas dos estudantes representaram o momento mais significativo dos círculos epistemológicos, pois traduziram muitas de suas angústias e inquietações que antes não tinham sido reveladas a ninguém que pertencesse ao espaço escolar. Entre as explanações, foi-nos permitido aproximar nossa pesquisa de queixas que manifestaram incompreensão sobre a falta de atitude da escola diante de reclamações de alunas e alunos a respeito de repetidas ocorrências danosas ao convívio entre estudantes. Cansados de esperar por alguma intervenção escolar alguns estudantes sinalizaram que frente à pequena intervenção da escola, desejavam elaborar o que ainda chamavam de "documento" sobre como se comportar na escola e diziam: "acho que dessa vez elas (gestoras escolares) vão nos respeitar", (estudantes do 
segundo ano do Ensino Médio).

Mas vimos também aqueles alunos mais críticos que repudiavam violências físicas ou verbais por parte de outros estudantes e questionavam seus autores. Diziam já ser o momento de iniciar mudanças nas relações interpessoais escolares e repetiam que "a responsabilidade pela melhoria da escola e a 'culpa' das ocorrências também seriam deles", (estudantes do primeiro ano do Ensino Médio).

Nas exposições, nota-se que os interlocutores reconhecem que há problemas nas relações pessoais e que até aquele momento nada ou muito pouco havia sido feito para melhorar o convívio escolar. Essas falas permitiram entender que a gestão escolar não vem atuando na problemática dos conflitos ou das violências conforme os estudantes esperam. Também podemos abstrair das observações dos estudantes que, esse procedimento de pesquisa-ação, caracterizou-se como um exercício crítico sobre a razão das violências e suas consequências, e mais, que a superação das ocorrências frequentes e danosas entre os estudantes passaria pela mudança de postura de todas e todos que formam a realidade escolar.

A discussão sobre propostas e práticas de superação dos conflitos fluiu melhor no segundo grupo, composto por maioria feminina. Embora o primeiro círculo tenha observado desde o início das discussões que algo precisaria ser feito para que alunas e alunos não voltassem a agir com práticas desrespeitosas, pouco se avançou na formulação de possíveis códigos de relações para a escola. No primeiro círculo, as propostas giraram em torno de punições severas aos praticantes das violências e maiores investimentos na educação. Diziam que a escola deveria ser rígida e "expulsar quem desrespeitasse normas e combinados", e ainda, que "ao perceberem que alunos estavam sendo punidos por mau comportamento, com certeza a violência na escola diminuiria".

No grupo majoritariamente feminino muitos partilhavam desse entendimento, mas acreditavam também que somente a expulsão dos "transgressores" não adiantaria. Diziam ser preciso que as vítima de humilhações ou práticas de violência fossem assistidas, acompanhadas por um psicólogo na escola.

Outros, porém, demonstraram posicionamentos bastante punitivos. Desejavam que a escola passasse a obrigar alunos que "roubassem" ou "quebrassem" algum pertence dentro de seu espaço a pedir desculpas em público e a devolver o que pegou, e completavam: "Não pode sair barato pra quem apronta". Alguns demonstraram que são favoráveis a instalação de câmeras internas às salas de aula e que diante de determinadas ocorrências a gestão deveria chamar o responsável pelo ato ilícito para ver as gravações.

Essas exposições demonstraram ser forte a ideia de punir quem desobedece normas ou desrespeita alguém. Porém, foram orientados pelo animador do círculo - o pesquisador 
- a não confundirem a elaboração de códigos de relações com meras medidas coercitivas, uma vez que, na perspectiva dialógica, não se trata simplesmente de penalizar quem venha a ter algum desentendimento ou briga, mas de trabalhar a consciência do indivíduo a fim de que possa entender que atitudes violentas não são saudáveis para sua vida dentro e fora da escola. Mostramos também que as práticas propostas pelo grupo para superar conflitos não poderiam demandar valores, pois recursos financeiros em escola pública não se conseguem com facilidade e quando chegam são destinados a outras necessidades.

Os participantes, em alguns momentos, tiveram dificuldade para pensar ações de mudança sem práticas punitivas. Mas, uma vez instigados a repensar aquelas intervenções e humanizar as soluções numa perspectiva de restaurar relações e construir novas possibilidades capazes de transformar o ambiente escolar sem envolver custos e que substituíssem as punições que não educam, muitos se mostraram preocupados com práticas de preconceitos que acontecem entre os estudantes, reconhecendo-as como manifestações de ignorância fizeram suas propostas de intervenção.

A partir de então, propuseram ações que envolvessem toda escola. Uma delas foi a proposta de que em todos os anos e períodos escolares, logo no primeiro bimestre, um projeto a ser desenvolvido entre alunos de diversas classes promovesse a discussão sobre formas de preconceito e violência na escola. Outra ideia foi a de elaborar um projeto interdisciplinar que mostrasse "as belezas das diferenças". Outros ainda disseram que a escola poderia proporcionar momentos de formação a partir de exibição de filmes sobre racismo, homofobia, vandalismo e drogas, seguidos por debates e reflexões por serem atividades que todos gostam e se envolvem. Conforme destacaram, para eles essas "são atividades que levam a sério".

Algumas estudantes destacaram que em suas turmas têm jovens bolivianos e haitianos que diariamente são provocados e ofendidos por suas origens. Reconhecem que tais práticas se dão porque esses jovens imigrantes ingressaram às turmas quando os grupos já estavam formados. Sobre isso disseram: "Ninguém conversou com a gente antes. Eu acho que seria bom virar "regra" ter uma conversa antes com os alunos para receberem bem quem vem de fora, reforçar que eles já vêm em situações difíceis e que nós precisamos acolhê-los como gostaríamos de ser acolhidos em outros países. Preparar tanto quem vai receber quanto quem vai chegar também”.

Interessante que o que mais se destacou, nas discussões do primeiro círculo, foi o modo de lidar com características e culturas diferentes. Embora confusos nas formulações de alguns códigos de relações, havia demasiada preocupação em sanar atitudes preconceituosas e intolerantes. No segundo círculo, por outro lado, de forma mais objetiva, 
procurou-se sugerir práticas que fossem fáceis de realizar, que auxiliem na transformação dos comportamentos e resgatem o respeito nas relações. Estudantes destacaram a importância de atividades coletivas capazes de envolver alunos e turmas diferentes e sugeriram palestras na escola que ajudem a fazê-los enxergar onde estariam errando. Segundo esses, tais momentos visariam o desenvolvimento de empatia e aceitação entre si podendo ser dinâmicas ou jogos interativos dentro das aulas ou em intervalos. Outros, porém, relataram que o problema gerador de tanta ocorrência entre estudantes estava em não conhecerem outras realidades distintas de suas casas e escola. Literalmente uma estudante disse: "Nós não saímos deste 'mundinho'. O dia que fizermos visitas a museus como o afro (Afro Brasil) e o da resistência (Memorial da resistência) nós vamos entender o que o desrespeito e a não aceitação do 'diferente' podem fazer". E continuou a estudante: "A escola precisa fazer excursões assim, sempre!”. Um fato inusitado ocorreu naquele momento da discussão. Logo após a exposição da estudante, os participantes aplaudiram e gritaram, em sinal claro de concordância com essa última explanação.

Percebemos com os círculos epistemológicos que os estudantes estavam ávidos por serem ouvidos sobre suas angústias e inquietações. Segundo relatos dos sujeitos, foi nos encontros de grupos e na troca de suas ideias que aprendizados e desejos de transformações vieram à tona e uma outra concepção de escola passou a ser pensada. Os dois encontros que aconteceram foram marcados pelo exercício do diálogo e da reflexão; constituíram-se as últimas etapas da dinâmica dos círculos epistemológicos.

Nos encontros conclusivos dos círculos continuaram a ser garantidos aos sujeitos a autonomia, a liberdade de expressão, o livre posicionamento de ideias e compreensões, a capacidade de interferir e agir na transformação da realidade. Essas oportunidades de se manifestarem, contando suas experiências e pensando a transformação da realidade, permitiu-nos conhecê-los em suas histórias para além dos espaços da escola.

As discussões e os apontamentos naquela etapa confirmaram que a escola analisada é palco típico do ambiente conflituoso e violento, seja entre os próprios estudantes, seja entre estudantes e profissionais da educação. Ocorrências como as mencionadas revelaram que o universo desta pesquisa não é totalmente um ambiente em que as relações entre educandos, educadores e agentes da escola são tecidas harmoniosamente ou capazes de fomentar o diálogo e a valorização das experiências dos sujeitos.

Percebemos que o desejo em discutir as problemáticas da escola além da sala de aula é um fator presente nas falas dos estudantes, por outro lado, essa preocupação não é tão latente no cotidiano da escola.

Observou-se nas exposições que as violências entre estudantes são sustentadas pelo 


\section{Dialogia}

não reconhecimento da diversidade, pelo desrespeito e desconhecimento da outra pessoa e, segundo as colocações em grupos, somente a partir do diálogo e entendimento sobre o ser do outro se tornará possível instaurar um ambiente escolar mais equilibrado e sadio e assim iniciar a "cultura de paz". Demonstraram acreditar que momentos coletivos fomentados por diálogos comprometidos com o bem comum podem auxiliar no exercício crítico da razão daqueles, por exemplo, que desvalorizam o próximo simplesmente por ter características, origens ou histórias diferentes das do grupo

Dessa forma, das diferentes explanações nos círculos epistemológicos resultou a codificação de específicas práticas interventivas que objetivam colaborar com as ações escolares preexistentes no enfrentamento das violências. Sistematizamos 11 códigos de relações em forma de acróstico e entregamos à escola após a conclusão da pesquisa, constituindo assim a proposta de intervenção pedagógica, são eles:

I. Promover o diálogo;

II. Atividades conjuntas;

III. Unir-se às famílias;

IV. Libertar consciências;

V. Organizar encontros conscientizadores;
VI. Fomentar discussões interdisciplinares;

VII. Refletir sobre as ocorrências;

VIII. Empatia e compreensão;

IX. Integrar os que chegam;

X. Revisitar as experiências;

XI. Eliminar os preconceitos nas relações.

A proposta de intervenção em forma de um "guia" apresentou maneiras concretas de se colocar em prática cada um dos códigos elaborados. Os momentos estruturados em círculos nos possibilitaram melhor alcance dos significados e expressões obtidos no questionário e nas conversas coletivas. Encontrar nos diálogos com os estudantes uma maneira real de superar as violências naquele ambiente escolar sempre esteve presente nos momentos das discussões promovidas, pois constituiu o objetivo do trabalho produzir uma proposta de intervenção pedagógica e entregá-la à escola para contribuir com suas ações de superação dos problemas levantados pelos sujeitos da pesquisa.

Os círculos epistemológicos se caracterizaram como uma ferramenta criadora de condições para que os estudantes pudessem realizar inferências e se posicionar acerca das violências na escola, suas consequências e também sobre as práticas de enfrentamento assumidas.

\section{Considerações finais}

Este trabalho propôs-se a compreender o fenômeno das violências nas escolas, 
desenvolvidas entre os estudantes de Ensino Médio, e conhecer as práticas adotadas pela escola como formas de enfrentamento e superação dessas violências. Considerou-se que, embora a escola pratique formas de violências contra seus estudantes, existe uma estrutura muito superior a ela e que a coloca como reprodutora de suas ações, o Estado. A maior de todas as violências do Estado é o próprio Estado. Mas não se trata de qualquer estado, mas aquele concreto que, na sociedade atual do sistema do capital, funciona para privilegiar alguns grupos enquanto oprime a grande maioria.

Por meio de estudos e observações em campo, entramos na escola e nos aproximamos dos seus fatores causais e encontramos nela espaço para o desenvolvimento de práticas interventivas baseadas no diálogo, com vistas à superação dos problemas e romper com o ciclo de violências.

O trabalho empírico abarcou experiências que possibilitaram falas, despertaram percepções e delinearam ações. Os momentos empíricos de levantamento de dados resultaram também, por meio da pesquisa-ação, nas manifestações dos estudantes que, por sua vez, elaboraram a proposta de intervenção pedagógica para subsidiar as ações da escola na busca pela superação das violências. Dessa maneira, os participantes esquematizaram códigos de convivência a fim de restaurar as relações escolares e, pouco a pouco, somados aos esforços por mudanças de consciências e atitudes de toda e todos na escola, estabelecer um ambiente promotor de diálogo e praticante da cultura de paz.

Ficou evidenciado que os/as discentes estavam desejosos por estudos, projetos e ações que contribuíssem com o fim da passividade da escola frente aos desafios das violências.

A opção pelo diálogo como oportunidade para ouvir, entender e crescer juntos sempre esteve presente ao longo desta pesquisa, sendo pensado como ferramenta possibilitadora de ações transformadoras e promotoras da consciência cidadã altruísta a fim de desenvolver entre os educandos os sentimentos de solidariedade, valorização do outro em sua totalidade, respeito às diversidades, igualdade, justiça e paz.

Para finalizar, concluímos nosso artigo com as palavras proferidas por Dom Hélder Câmara ${ }^{3}$, no antigo Programa radiofônico "Um olhar sobre a cidade", veiculado pela Rádio Olinda, em 1974, sobre o ganho real em se praticar o diálogo:

Há temas aos quais é preciso voltar sempre. Um deles é a dificuldade e a necessidade importantíssima de autêntico diálogo. Recordemos uma verdade verdadeiríssima: "se discordas de mim tu me enriqueces". Se és sincero e buscas a verdade e tentas encontrá-la como podes, ganharás tendo a honestidade e a modéstia de completar teu pensamento com o pensamento mesmo de pessoas que te pareçam muito menos inteligentes e cultas do que tu. ${ }^{4}$ 
O trabalho tenciona que o diálogo se torne realidade presente nas relações pessoais tecidas dentro e fora das escolas. Que cada vez mais os seres "históricos e inacabados", como dizia Freire (1996), busquem com sinceridade a verdade sobre o mundo e sobre si mesmos: mulheres, homens e demais gêneros; crianças, idosos e demais fases; negros, brancos e demais etnias possam completar sua existência com as múltiplas riquezas dos outros.

\section{Referências}

ABRAMOVAY, Miriam. Violências no cotidiano das escolas. In ABRAMOVAY, Miriam et al. Escola e violência. Brasília, DF: Unesco, 2002. p. 67-86.

BOURDIEU, Pierre; PASSERON, Jean-Claude. A reprodução: Elementos para uma teoria do sistema de ensino. Trad. de Reynaldo Bairão. Rio de Janeiro: Francisco Alves,1982.

BOURDIEU, Pierre. O poder simbólico. Lisboa: Difel, 1989.

DAHLBERG, Linda; KRUG, Etienne. Violência: um problema global de saúde pública. Ciência e Saúde Coletiva, Rio de Janeiro, v. 11, suplemento, p. 1163-1178, 2006.

DURKHEIM, Émile. Educação e Sociologia. São Paulo: Edições 70, 2015.

FREIRE, Paulo. Educação como prática da Liberdade. Rio de Janeiro: Paz e Terra, 1967.

FREIRE, Paulo. Conscientização: teoria e prática da libertação. São Paulo: Cortez, 1979

FREIRE, Paulo. Pedagogia do oprimido. Rio de Janeiro: Paz e Terra, 1987.

FREIRE, Paulo. Cartas a Cristina. São Paulo: Paz e Terra, 1994.

FREIRE, Paulo. Pedagogia da autonomia: saberes necessários a prática educativa. São Paulo: Paz e Terra, 1996.

FREIRE, Paulo; FAUNDEZ, Antônio. Por uma Pedagogia da Pergunta. 3. ed. Rio de Janeiro: Paz e Terra, 1985.

GADOTTI, Moacir. Paulo Freire: uma bibliografia. São Paulo: Cortez/Instituto Paulo Freire; Brasília, DF: UNESCO, 1996.

PRIOTTO, Elis Palma. Violência escolar: políticas públicas e práticas educativas no município de Foz do Iguaçu. Cascavel: Edunioeste, 2011.

ROMÃO, José Eustáquio et al. Círculo epistemológico: círculo de cultura como Metodologia de Pesquisa. São Paulo: IPF, 2006. Disponível em http://www.metodista.br/ppc/educacao-elinguagem/educacao-e-linguagem-13/circuloepistemologico-circulo-de-cultura-comometodologia-de-pesquisa/. Acesso em: 21 jan. 2019. 
${ }^{1} \mathrm{O}$ presente artigo tem como base a dissertação de mestrado "Violências entre pares no contexto escolar: razões e enfrentamentos”, defendida no Programa de Pós-Graduação Profissional em Educação "Gestão e Práticas Educacionais" (PROGEPE), da Universidade Nove de Julho (UNINOVE - 2019).

${ }^{2}$ Survey é um método de pesquisa que visa a obtenção de dados ou informações sobre características, ações ou opiniões de determinado grupo de pessoas, indicado como representante de uma população alvo, por meio de um instrumento de pesquisa, normalmente um questionário. Conferir em: https://pt.surveymonkey.com

${ }^{3}$ Dom Hélder Pessoa Câmara (Fortaleza, 7 de fevereiro de 1909 - Recife, 27 de agosto de 1999) foi um Bispo católico, Arcebispo emérito de Olinda e Recife. Entre outras importantes atuações, destacou-se como grande defensor dos direitos humanos durante a ditadura militar no Brasil. Através de seus Escritos, Dom Hélder denunciava e combatia todas as formas de violência, de exclusão e de opressão, incentivando a solidariedade, o respeito à vida e estimulando o exercício da cidadania. Foi indicado quatro vezes para o Prêmio Nobel da Paz pelo seu combate à ditadura e às torturas no Brasil, mas impedido de receber a honraria por intensa campanha contrária articulada pelos governos militares brasileiros. Disponível em: http://institutodomhelder.blogspot.com/2015/04/instituto-dom-helder-camara-idhec.html. Acesso em: 13 jan. 2019.

${ }^{4}$ Transcrição de uma das mensagens de Dom Hélder Câmara no Programa de Rádio "Um olhar sobre a cidade", 1974. Disponível em: http://domtotal.com/video.php?mulArqId=65\&mulId=29. Acesso em: 13 jan. 2019.

Recebido em: 20 jun. 2019 / Aprovado em: 03 jul. 2019

\section{$\underline{\text { Cite como }}$}

BRITTO, Éder Soares Sá; MAFRA, Jason Ferreira. Violências entre pares no contexto escolar: razões e enfrentamentos. Dialogia, São Paulo, n. 32, p. 165-182, maio/ago. 2019. Disponível em: https://doi.org/10.5585/Dialogia.n32.14323. 